\title{
An Educational Intervention, Involving Feedback of Routinely Collected Computer Data, to Improve Cardiovascular Disease Management in UK Primary Care
}

\author{
S. de Lusignan \\ Primary Care Informatics, Division of Community Health Sciences, St. George's, University of London, \\ London, UK
}

\begin{abstract}
Summary
Objectives: To report the lessons learned from eight years of feeding back routinely collected cardiovascular data in an educational context

Methods: There are distinct educational and technical components. The educational component provides peer-led learning opportunities based on comparative analysis of quality of care, as represented in computer records. The technical part ensures that relevant evidence-based audit criteria are identified; an appropriate dataset is extracted and processed to facilitate quality improvement. Anonymised data are used to provide inter-practice comparisons, with lists of identifiable patients who need interventions left in individual practices.

Results: The progressive improvement in cholesterol management in ischaemic heart disease (IHD) is used as an exemplar of the changes achieved. Over three iterations of the cardiovascular programme the standardised prevalence of IHD recorded in GP computer systems rose from $3.8 \%$ to $4.0 \%$. Cholesterol recording rose from $47.6 \%$ to $89.0 \%$; and the mean cholesterol level fell from 5.18 to $4.67 \mathrm{mmol} / \mathrm{L}$; while statin prescribing rose from $46 \%$ to $57 \%$ to $68 \%$. The atrial fibrillation, heart failure and renal programmes (more people with chronic kidney disease go on to die from cardiovascular cause than from end-stage renal disease) are used to demonstrate the range of cardiovascular interventions amenable to this approach. Conclusions: Technical progress has meant that larger datasets can be extracted and processed. Feedback of routinely collected data in an educational context is acceptable to practitioners and results in quality improvement. Further research is needed to assess its utility as a strategy and cost-effectiveness compared with other methods.
\end{abstract}

\section{Keywords}

Computers, ischemic heart disease, quality of healthcare, computerised medical record systems, cholesterol

Methods Inf Med 2007; 46: 57-62

\section{Introduction}

UK general practice is computerised and quality targets based on computer data provide incentives to improve data quality [1]. Despite this, routinely collected data is an underused resource and there remains scope to further improve computer data quality [3-5]. Our approach to quality improvement is to use an educational intervention based on feedback of routinely collected data and what it says about the quality of care [6-9]. We use a range of methods of feedback to provide a range of learning opportunities to match the likely range of learning styles of primary care professionals. It incorporates the use of: the theory of diffusion of innovations [10, 11], academic detailing [12], adult learning theory [13] and what are known to be effective methods of feedback [14].

Cardiovascular (CVS) disease is an important cause of morbidity and mortality worldwide and has been the principal area within which our intervention has been tested. There is a range of evidence-based interventions available to primary care, which can make a difference to outcome. These include: improving cholesterol management in patients with ischaemic heart disease [15], monitoring high-risk patients with atrial fibrillation (AF) receiving anticoagulant therapy [16] and tackling cardiovascular risk in people with chronic kidney disease (CKD), much of which is under treated [17]. Many more people with CKD suffer preventable cardiovascular disease than go on to end-stage renal disease [18].

This paper reports the lessons from over eight years of working with general practice data and feeding it back, in an educational context, to improve the quality of care. Improved cholesterol management in ischaemic heart disease (IHD) and using computer searches to identify suboptimally managed cardiovascular risk, people with $\mathrm{AF}$ [9] and CKD [19] are used as exemplars of the practical application of this work.

\section{Methods}

The method used in the Primary Care Data Quality (PCDQ) programme has two components: design of an educational intervention and a technical process (see Fig 1).

The design of the educational intervention provides clinically relevant feedback to clinicians and overview statistics to local health service managers and researchers. We design separate interventions for each clinical area we work in, looking to provide an innovative way that evidence care might be improved. We look to work with opinion leaders within a locality, to influence those likely to be early adopters of change $[10,11]$ and, where appropriate, support the implementation of evidence-based national targets. Carefully designed academic detailing supports each clinical programme, we keep the volume of data fed back brief with an educational focus [12]. A different visual appearance is adopted for each variable and a gentle sense of competition is created by comparing the performance of each practice [13]. The programmes are run in a nonjudgemental learning environment, which seeks to follow a learner-centred shared problem-solving orientation. Wherever pos- 


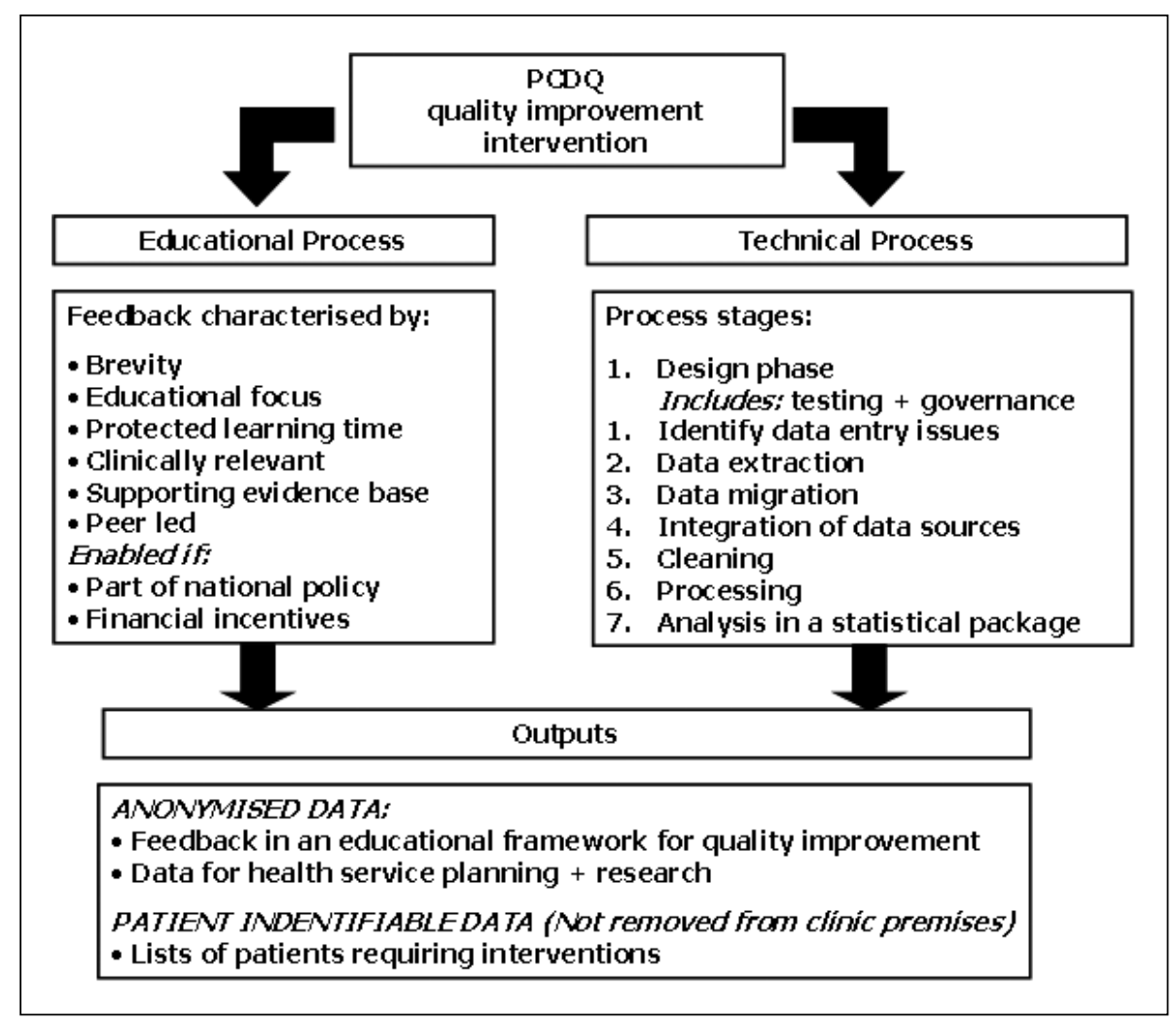

Fig. 1 The PCDQ educational and technical processes

sible this takes place in protected learning time at locally led, half-day, data quality workshops (DQW). The programmes are implemented in areas where there is clinical need, an evidence-base and interventions to improve quality [14]. The feedback process has been designed and developed to increase its chances of success.

The Data Quality Workshop (DQW) is also supported by other interventions. We provide graphical summaries of data to each practice, indicating how their data quality compares with their peers, a summary spreadsheet of practice data quality sent to the local primary care organisation, with the consent of the practices and Field staff provide basic one-to-one Read code training for primary care professionals, if needed. We also invite each locality where the programme operates to the annual PCDQ Forum. This is a two-day action research workshop where we ask for comments on the strengths and weaknesses of the programme and plan future developments accordingly.
3) Data extraction: We routinely use MIQUEST [23] (Morbidity Information Query and Export Syntax - a Department of Health sponsored data extraction tool) to take out data from general practice systems.

4) Migration: Data is usually extracted using a physical transfer medium, e.g. floppy disk and migrated into a format whereby it can be integrated into the data repository.

5) Integration: Different data tables, data about subsets of patients with one disease, serial data collections all have to be linked, so that the project outputs can be delivered. We also de-duplicate at this stage.

6) Cleaning: Here the issue of out of range values, inconsistencies such as data entry in more than one type of unit (e.g. heights in centimetres and metres) and other problems with the data are addressed.

7) Processing: Processing involves the conversion of extracted code into the plain English text assigned to that code by the coding system; e.g. the code $\mathrm{H} 3 \mathrm{z}$ into "chronic obstructive pulmonary disease". It involves grouping these into categories relevant to the intended analysis.

8) Analysis: The output from the processing stage is usually a "flat file". This will have one line per patient data and variables in columns. The first stage is to assess the quality of the data (completeness, accuracy, consistency, currency) [24] and where appropriate to calculate the sensitivity and positive predictive value of diagnostic and prescribing data [4]. Automated reports are generated from this data for feedback to practices or localities or flat-file data tables for research, which are migrated into a standard statistical package. or information governance and data protection issues. Finally, test data is extracted and processed and the lessons fed back into the design process.

2) Data entry issues: Our methodological approach takes account of data entry issues as they can have a profound effect on the way that patients with the same clinical conditions are represented within the computer system. 
Feedback to Improve CVD Management

ing cardiovascular risk in patients with undetected chronic kidney disease (CKD).

The programmes in AF and CKD differed from the IHD programme in that we stratified risk by processing data outside the GP computer system. Most GPs and practice nurses are familiar with estimating risk in IHD using the appropriate risk factors and are often assisted by their computer system in performing these calculations. In the $\mathrm{AF}$ and $\mathrm{CKD}$ programmes, we used standard algorithms to calculate and stratify risk outside the computer system. This meant not only did we have to feedback these data and what they said about the quality of care, but we also had to explain how we had calculated risk. In AF, although we found an increase in prevalence of the disease, most of the patients were already identified in the GP computer records and practitioners were aware of the evidence-base. In CKD we identified that $5 \%$ of practice populations have decline in kidney function and that the practices are neither aware of this condition or the evidence-base for interventions to improve cardiovascular risk. The increasing complexity of the educational challenge in these three programmes is set out in Table 1.

Practices participating in the PCDQ cardiovascular programme have progressively improved their management of cholesterol. More patients are diagnosed with IHD, more have their cholesterol measured and a greater proportion are treated with cholesterol-lowering therapy and achieve the target set for cholesterol lowering. Practi- tioners are generally aware of the evidencebase for intervention in this condition, which is set out in national guidance [25]. Many of the general practitioner electronic patient record systems (EPR) automatically calculate risk and risk factor calculation tables are also provided in the standard UK drug dictionary [26], which is provided free to all GPs. Data showing the progressive reduction of cholesterol targets are shown in Table 2. The standardised prevalence of IHD recorded in GP computer systems rose from $3.8 \%$ to $4.0 \%$. Cholesterol recording rose from $47.6 \%$ to $89.0 \%$ and the mean cholesterol level fell from 5.18 to $4.67 \mathrm{mmol} / \mathrm{L}$ in people with IHD. Meanwhile statin prescribing rose from $49.4 \%$ to $71.5 \%$. The proportion of patients reaching the $5 \mathrm{mmol} / \mathrm{L}$ target has improved by $11 \%$ each year rising from $46 \%$ to $57 \%$ to $68 \%$ year on year [27]. The intervention appears to be welcomed by participating clinicians [28].

Our atrial fibrillation (AF) quality improvement programme was the first in which we calculated risk outside the GP computer record [9]. We stratified patients by their level of risk of stroke using evidence-based guidance something our GP colleagues were not familiar with undertaking. We found that females received suboptimal care because insufficient account was being taken of their risk of stroke. As in IHD, we found a higher prevalence of disease than reported in previous studies. The age-standardised prevalence of diagnosed atrial fibrillation was $1.23 \%$ (1.28\% for men and $1.18 \%$ for women). $46 \%$ of men and $37 \%$ of women were prescribed Warfarin or had contraindications to its use. The lower proportion of women being treated is statistically significant (Chi-square $\mathrm{p}<0.001$ ). Of the people with $\mathrm{AF}$ prescribed Warfarin only three-quarters $(75.9 \%)$ have an INR (International Normalised Ratio) in range. $44 \%$ were treated with aspirin. People at high risk of stroke were no more likely to be treated with Warfarin or aspirin than those at moderate risk and care of females was suboptimal compared with males. These findings were challenging for GP colleagues, who were generally aware of the evidence but were not implementing it within their practices [30].

Our investigation of the quality of care in chronic kidney disease (CKD) revealed that this condition was largely undiagnosed and there was scope to improve the management of cardiovascular co-morbidity and risk. Although many people with CKD go on to suffer from end-stage renal disease, only $4 \%$ require renal replacement, a much greater proportion (46\%) die from cardiovascular disease [31]. CKD is diagnosed by measuring renal function. One of the simplest ways of doing this is to estimate glomerular filtration rate (GFR) from serum creatinine, age, gender and ethnicity. A GFR of less than $60 \mathrm{ml} / \mathrm{min} / 1.73 \mathrm{~m}^{2}$ is diagnostic of CKD, though the diagnosis can still be made with a higher (and nearer to normal) GFR if there is evidence of renal damage.

Table 1 Increasing complexity of educational interventions in IHD, AF and CKD

\begin{tabular}{|c|c|c|c|c|c|}
\hline Clinical condition & $\begin{array}{l}\text { Change in recorded } \\
\text { prevalence }\end{array}$ & $\begin{array}{l}\text { Practitioner awareness of } \\
\text { evidence-base }\end{array}$ & Risk calculation & $\begin{array}{l}\text { Implementation of } \\
\text { guidance }\end{array}$ & $\begin{array}{l}\text { Complexity of change } \\
\text { required }\end{array}$ \\
\hline $\begin{array}{l}\text { IHD } \\
\text { Ischaemic Heart Disease }\end{array}$ & $\begin{array}{l}\text { Increased 10\% } \\
\text { (from 3.8\% to 4.2\%) }\end{array}$ & $\begin{array}{l}\text { Good } \\
\text { National Service Framework } \\
\text { (CHD NSF) }\end{array}$ & $\begin{array}{l}\text { Widely available } \\
\text { Within GP EPR } \\
\text { In standard drug dictionary } \\
\text { (BNF) }\end{array}$ & $\begin{array}{l}\text { Some scope for } \\
\text { improvement } \\
\text { Context of on-going } \\
\text { improvement }\end{array}$ & $\begin{array}{l}\text { + Routine } \\
\text { Recognition still a gap in } \\
\text { quality of care }\end{array}$ \\
\hline $\begin{array}{l}\text { AF } \\
\text { Atrial Fibrillation }\end{array}$ & $\begin{array}{l}\text { Increased } 10-15 \% \\
\text { Compared with other studies }\end{array}$ & $\begin{array}{l}\text { Good } \\
\text { Good awareness of evidence } \\
\text { in literature }\end{array}$ & $\begin{array}{l}\text { Outside GP system by } \\
\text { PCDQ }\end{array}$ & $\begin{array}{l}\text { Considerable scope for } \\
\text { improvement }\end{array}$ & $\begin{array}{l}++ \text { Moderate } \\
\text { Not stratifying by risk, large } \\
\text { proportion scope to improve } \\
\text { care }\end{array}$ \\
\hline $\begin{array}{l}\text { CKD } \\
\text { Chronic Kidney Disease }\end{array}$ & $\begin{array}{l}\text { Increased } 27 \text {-fold } \\
\text { Only } 3.6 \% \text { was previously } \\
\text { diagnosed }\end{array}$ & $\begin{array}{l}\text { Poor } \\
\text { No literature but experience } \\
\text { is GPs are distressed by their } \\
\text { lack of knowledge }\end{array}$ & $\begin{array}{l}\text { Outside GP systems by } \\
\text { PCDQ }\end{array}$ & $\begin{array}{l}\text { Little evidence of any } \\
\text { systematic implementation } \\
\text { of guidance }\end{array}$ & $\begin{array}{l}+++ \text { High } \\
\text { Learn evidence Large number } \\
\text { of undiagnosed and } \\
\text { suboptimally managed }\end{array}$ \\
\hline
\end{tabular}


Table 2 Progressive improvement in cholesterol management in people with ischaemic heart disease in the PCDQ programme

\begin{tabular}{|c|c|c|c|c|c|c|c|c|c|}
\hline & \multicolumn{3}{|c|}{ Cholesterol recorded } & \multicolumn{3}{|c|}{ Cholesterol value } & \multicolumn{3}{|c|}{ Taking a statin } \\
\hline & 2002 & 2003 & 2004 & 2002 & 2003 & 2004 & 2002 & 2003 & 2004 \\
\hline & $N(\%)$ & $\mathrm{N}(\%)$ & $\mathrm{N}(\%)$ & mean (SD) & mean (SD) & mean $(S D)$ & $\mathrm{N}(\%)$ & $N(\%)$ & $\mathrm{N}(\%)$ \\
\hline $0-24$ & 10 & $0(0.0)$ & $3(11.1)$ & $5.89(2.18)$ & - & $4.77(1.31)$ & $5(50.0)$ & $0(0.0)$ & $1(3.7)$ \\
\hline$\overline{25-44}$ & $708(45.7)$ & $110(41.4)$ & $269(74.9)$ & $5.23(1.32)$ & $5.05(1.23)$ & $4.92(1.22)$ & $334(47.2)$ & $132(49.6)$ & $225(62.7)$ \\
\hline $45-64$ & $13,725(56.1)$ & $2,764(72.7)$ & $5360(92.3)$ & $5.16(1.15)$ & 4.98 (1.10) & $4.72(1.01)$ & 7171 (52.2) & $2,917(76.7)$ & $4,690(80.8)$ \\
\hline $65-84$ & $26,630(49.5)$ & $6,953(72.8)$ & $11,738(91.7)$ & $5.18(1.16)$ & 4.86 (1.08) & $4.62(1.00)$ & $13,028(48.9)$ & $6,707(70.3)$ & $9,447(73.8)$ \\
\hline$>85$ & 1,470 (15.3) & $602(33.5)$ & $1,330(65.5)$ & $5.55(1.23)$ & 5.25 (1.28) & $4.91(1.15)$ & $450(30.6)$ & $544(30.2)$ & $671(33.1)$ \\
\hline$\overline{\text { All }}$ & $42,533(47.6)$ & $10,429(67.6)$ & $18,700(89.0)$ & $5.18(1.71)$ & $4.91(1.10)$ & $4.67(1.02)$ & $20,987(49.4)$ & $10,300(66.7)$ & $15,034(71.5)$ \\
\hline$p$ & & & & & $p<0.001^{*}$ & $p<0.001^{*}$ & & $p<0.001^{* *}$ & $p<0.001^{* *}$ \\
\hline
\end{tabular}

One quarter of the population $(25.7 \%$; $28,862 / 112,215)$ had a serum creatinine recorded in their computer record enabling us to calculate their GFR. One in five $(18.9 \%)$ had a GFR $<60 \mathrm{ml} / \mathrm{min} / 1.73 \mathrm{~m}^{2}$, which is diagnostic of CKD. This represents $4.9 \%$ of the population. Three-quarters $(74.6 \%$; $4,075 / 5,449$ ) of those with CKD had one or more circulatory diseases and risk factors amenable to intervention in primary care. For example: The mean systolic blood pressure in those with a normal GFR was $130 \mathrm{mmHg}$ while for those with a GFR $<60 \mathrm{ml} / \mathrm{min} / 1.73 \mathrm{~m}^{2}$ systolic BP was $142 \mathrm{mmHg}$. One-way analysis of variance shows that the differences were significant at the $p<0.001$ level. Evidence-based guidance recommends lowering BP in CKD to $130 \mathrm{mmHg}$. Similarly, people with diabetes and CKD were more obese, mean body mass index was $30 \mathrm{~kg} / \mathrm{m}^{2}$ compared with those without CKD where it was $27 \mathrm{~kg} / \mathrm{m}^{2}$. There is considerable scope for intervention and improvement of risk factors. Only 3.6\% of these people were recorded as having renal disease within the GP computer record. A subsequent hand-search of 500 records in one practice suggested the computer results were reliable with only four more cases having an indication that they had CKD only in their written records (i.e. not transferred into the computer record.)

Primary care professionals involved in the CKD programme had four challenges: GPs had no idea that the prevalence of CKD was so high $(5 \%)$; they were not familiar with the evidence-base; the stratification of risk took place outside the computerised medical record using a method with which they were unfamiliar; and they were found lacking in implementing best practice. Part of the reason we undertook the hand-search of 500 records was to generate evidence to overcome the cognitive dissonance of GPs that such a large number of people might have undiagnosed CKD.

\section{Discussion}

Improvements in data quality and the capacity and capability of information and communications technologies mean that progressively more use can be made of routinely collected general practice computer data. We are able to achieve ever more complex processing of routinely collected data including manipulating large and complex datasets outside the GP computer system. These data can be used to identify high-risk groups and be used by practitioners to improve the quality of care in IHD, AF and CKD. However, for health services to derive more benefit from this data our assertion is that there needs to be an accompanying educational programme. Education provides the right non-judgmental medium through which clinicians can readily engage in quality improvement. Focussing on data quality alongside the quality of care enables primary care to work towards having computerised medi- cal records, which accurately reflect the quality of care. This is particularly important in England where we are moving towards an integrated healthcare computer system, with data entered in one part of the health service being accessible in another [34]. Feedback of routinely collected data, in an educational context, has a place in the tools available to raise data quality and the quality of clinical care. The PCDQ audit-based educational approach provides a working model of such an intervention.

Although general practice computer data are becoming more readily available they have limitations $[4,5,20]$. The wider challenges of working with every more accessible clinical data are well described [35]. Specifically, with general practice data there are: problems with the denominator, which is known to be inflated [36]; data are inevitably incomplete for a variety of reasons and missing data requires careful interpretation. Other factors can also improve data quality, for example: financial incentive; reducing the number of different computer systems that practitioners use [37]; and looking to achieve more standardisation in the approach to managing conditions.

Although we have not tested this intervention with and without comparative feedback between practices, our perception is that this is also a powerful motivator for change. A randomised controlled trial has shown that feedback has been more effective than just information in the management of hypertension [38]. It is likely that 
the lessons from this study are transferable to other cardiovascular diseases. The rise in statin prescription in the PCDQ populations was larger than that reported in the Healthwise II study, which principally provided clinical assessment without education [39]. $49 \%$ were treated on statins at the start of Healthwise rising to $57 \%$ compared with a rise from the same starting point with PCDQ from $49.4 \%$ to $71.5 \%$, though we accept our study has taken place over a longer period with more iterations. As with many interventions it has not been fully or systematically evaluated [40].

Clearly, other factors are important in using computerised systems to improve the quality of care many of which are recognised internationally [41]. These include organisational factors, which include: the use of financially incentivised quality targets; improving technical issues like the coding interface within clinical systems; standardising the coding system; and the motivation and technical ability of the primary care clinician to code data. More research is needed to explore the relative effectiveness and cost-effectiveness of different types of intervention.

\section{Conclusions}

The PCDQ programme has demonstrated effectiveness in improving the management of IHD and in finding people in $\mathrm{AF}$ and with $\mathrm{CKD}$ at increased cardiac risk. Feedback in an educational context, underpinned by a highly developed technical process provides the necessary synergy to promote quality improvement.

\section{Acknowledgements}

The members of the Primary Care Informatics Team; funders of which MSD has been the largest through a series of unconditional educational grants; and participants in the PCDQ programme.

\section{References}

1. Department of Health. Primary Care Contracting - Quality and Outcomes Framework (QOF). URL: http://www.dh.gov.uk/PolicyAndGuidance/ OrganisationPolicy/PrimaryCare/PrimaryCare Contracting/fs/en
2. de Lusignan S, van Wheel C. The use of routinely collected computer data for research in primary care: opportunities and challenges. Fam Pract 2006; 23 (2): 253-63.

3. de Lusignan S, Wells S, Hague N, Thiru K. Managers see the problems associated with coding clinical data as a technical issue whilst clinicians also see cultural barriers. Methods Inf Med. 2003; 42 (4): 416-22.

4. Falconer E, de Lusignan S. An eight step method for assessing diagnostic data quality in practice: Chronic obstructive pulmonary disease (COPD) as an exemplar. Informatics in Primary Care 2004: $12(4) ; 243-53$.

5. de Lusignan S, Valentin T, Chan T, Hague N, Wood O, Dhoul N. Problems with primary care data quality: Osteoporosis as an exemplar. Informatics in Primary Care 2004: 12 (3); 147-56.

6. de Lusignan S, Belsey J, Hague N, Dhoul N, van Vlymen J. The "rule of halves" still applies to the management of cholesterol in cardiovascular disease : 2002-2005. British Journal of Cardiology 2006; 13 (2): 145-52.

7. de Lusignan S, Belsey J, Hague N, Dzregah B. End digit preference in blood pressure recordings of patients with ischaemic heart disease in primary care. Journal of Human Hypertension 2004; 18: 261-5.

8. de Lusignan S, Hague N, Brown A, Majeed A. An educational intervention to improve data recording in the management of ischaemic heart disease in primary care. Journal of Public Health 2004; 28 (1): 34-7.

9. de Lusignan S, Van Vlymen J, Hague N, Thana L, Chan T, Dzregah B. Preventing stroke in people with atrial fibrillation: a cross-sectional study. J Public Health (Oxf) 2005; 27 (1): 85-92.

10. Rogers E. Diffusion of Innovations. 4th ed. New York: Free Press; 1995.

11. Berwick DM. Disseminating innovations in health care. JAMA 2003; 289 (15): 1969-75.

12. Soumerai SB, Avorn J. Principles of educational outreach ('academic detailing') to improve clinical decision making. JAMA 1990; 263 (4): 549-56.

13. Davis D. Clinical practice guidelines and the translation of knowledge: the science of continuing medical education. CMAJ 2000; 163 (10): 1278-9.

14. NHS Centre for Reviews and Dissemination, University of York. Getting evidence into practice. Effective Healthcare 1999, 5(1). URL: http://www. york.ac.uk/inst/crd/ehc51.pdf

15. Law MR, Wald NJ, Rudnicka AR. Quantifying effect of statins on low density lipoprotein cholesterol, ischaemic heart disease, and stroke: systematic review and meta-analysis. BMJ 2003; 326 (7404): 1423.

16. Stewart S, Murphy N, Walker A, McGuire A, McMurray JJ. Cost of an emerging epidemic: an economic analysis of atrial fibrillation in the UK. Heart 2004; 90 (3): 286-92.

17. John RI, Webb MC, Young A, Stevens PE. Unreferred chronic kidney disease: A longitudinal study. Am J Kidney Dis 2004; 43: 825-35.
18. Coresh J, Astor BC, Greene T, Eknoyan G, Levey AS. Prevalence of chronic kidney disease and decreased kidney function in the adult US population: Third National Health and Nutrition Examination Survey. Am J Kidney Dis 2003; 41 (1): $1-12$

19. de Lusignan S, Chan T, Stevens P, O'Donoghue D, Hague N, Dzregah B, Van Vlymen J, Walker M, Hilton S. Identifying patients with chronic kidney disease from general practice computer records. Fam Pract 2005; 22 (3): 234-41.

20. van Vlymen J, de Lusignan S, Ensuring the quality of aggregated general practice data: lessons from the Primary Care Data Quality Programme (PCDQ). MIE Europe 2005

21. Berndt DJ, Fisher JW, Hevner AR, Studinicki J. Healthcare data warehousing and quality assurance. IEEE Computer 2001; 34 (12): 56-65.

22. Wang RY, Strong DM. Beyond accuracy: what data quality means to data consumers. Journal of Management Information Systems 1996; 12 (4): 5-34.

23. Clinical Information Consultancy. MIQUEST and Health query language. URL: http://www. clininfo.co.uk/main/miquest.htm

24. de Lusignan S, Teasdale S. Data quality probes as used display many of the features of an effective data quality programme. Journal Informatics in Primary Care 2003: 11 (4): 234-7.

25. Department of Health. National Service Framework for Coronary Heart Disease (Ref: 166021P30K). London: Department of Health, 2000. URL: http://www.dh.gov.uk/PolicyAnd Guidance/HealthAndSocialCareTopics/Coronary HeartDisease/fs/en

26. British Medical Association, Royal Pharmaceutical Society. British National Formulary (BNF). URL: http://www.bnf.org

27. de Lusignan S, Hague N, Belsey J, van Vlymen J. Progressive achievement of cholesterol targets in general practice makes further reductions feasible: report of cross-sectional data 2002-4. URL: http://www.pcel.info/index.cfm? fuseaction $=$ home.indexcard\&id $=1263$

28. de Lusignan S, Hague N, Yates C, Harvey M. A case study from a Sussex Primary Care Group: improving secondary prevention in coronary heart disease using an educational intervention. British Journal of Cardiology 2002; 9 (6): 362-8.

29. SIGN (Scottish Inter-collegiate Guidelines Network) Publication Number 36. Antithrombotic Therapy; pp 19-22. URL: http://www.sign.ac.uk/ pdf/sign36.pdf

30. Freeman AC, Sweeney K. Why general practitioners do not implement evidence: qualitative study. BMJ 2001; 323: 1100-2.

31. Drey N, Roderick P, Mullee M, Rogerson M. A population-based study of the incidence and outcomes of diagnosed chronic kidney disease. Am J Kidney Dis 2003; 42: 677-84

32. The sixth report of the Joint National Committee on prevention, detection, evaluation, and treatment of high blood pressure. Arch Intern Med 1997; 157 (21): 2413-46. 
33. Anandarajah S, Tan T, de Lusignan S, Stevens P. O'Donoghue D, Wlker M, Hilton S. The validity of searching routinely collected general practice computer data to identify patients with chronic kidney disease (CKD): a manual review of 500 medical records. Nephrol Dial Transplant 2005; 20 (10): 2089-96.

34. National Health Service. Connecting for Health. URL: http://www.cfh.nhs.uk

35. Bott OJ, Ammenwerth E, Brigl B, Knaup P, Lang E, Pilgram R, Pfeifer B, Ruderich F, Wolff AC, Haux R, Kulikowski C. The challenge of ubiquitous computing in health care: technology, concepts and solutions. Findings from the IMIA Yearbook of Medical Informatics 2005. Methods Inf Med 2005; 44 (3): 473-9.

36. Ashworth M, Jenkins M, Burgess K, Keynes H, Wallace M, Roberts D, Majeed A. Which general practices have higher list inflation? An exploratory study. Fam Pract 2005; 22 (5): 529-31.

37. Williams P, de Lusignan S. Quality points are not associated with the quality of care in stroke. Inform Prim Care 2006; 14 (1): 29-40.

38. Mitchell E, Sullivan F, Grimshaw JM, Donnan PT, Watt $\mathrm{G}$. Improving management of hypertension in general practice: a randomised controlled trial of feedback derived from electronic patient data. Br J Gen Pract. 2005; 55 (511): 94-101.

39. Brady AJ, Pittard JB, Grace JF, Robinson PJ. Clinical assessment alone will not benefit patients with coronary heart disease: failure to achieve cholesterol targets in 12,045 patients- the Healthwise II study. Int J Clin Pract 2005; 59 (3): 342-5.

40. Rigby M. Evaluation - The Cinderella Science of ICT in Health. Methods Inf Med 2006; 45 (Suppl 1): 141-20.
41. Knaup P. Electronic Patient Records and their Benefit for Patient Care. Methods Inf Med 2006; 45 [Suppl 1]: 40-2.

Correspondence to:

S. de Lusignan

Primary Care Informatics

Division of Community Health Sciences

6th Floor Hunter Wing

St. George's, University of London

London, SW17 ORE

UK

E-mail: slusigna@sgul.ac.uk 